\title{
Pyridoxal Phosphate Measurement
}

National Cancer Institute

\section{Source}

National Cancer Institute. Pyridoxal Phosphate Measurement. NCI Thesaurus. Code C158237.

The determination of the amount of pyridoxal phosphate present in a sample. 